\title{
The Importance of Classical and Molecular Cytogenetics in the Diagnosis of Microdeletions Microduplications Syndromes
}

\section{CRISTINA ANNEMARIE POPA ${ }^{1}$, MARIA PUIU ${ }^{1}$, NICOLETA IOANA ANDREESCU ${ }^{1}$, DANIEL POPA ${ }^{2 *}$, GEORGE PUENEA ${ }^{2}$, EMIL FLORIN HUT ${ }^{3}$, SMARANDA TEODORA ARGHIRESCU ${ }^{4}$}

${ }^{1}$ Victor Babes University of Medicine and Pharmacy, Discipline of Genetics, 2 Eftimie Murgu Sq., 300041, Timisoara, Romania.

${ }^{2}$ Victor Babes University of Medicine and Pharmacy, Discipline of Medical Rehabilitation, 2 Eftimie Murgu Sq., 300041, Timisoara, Romania

${ }^{3}$ Victor Babes University of Medicine and Pharmacy, Department of Surgery 1, 2 Eftimie Murgu Sq., 300041, Timisoara, Romania

${ }^{4}$ Victor Babes University of Medicine and Pharmacy, Discipline of Paediatrics, 2 Eftimie Murgu Sq., 300041, Timisoara, Romania

Abstract. Microdeletions and microduplications syndromes are a well defined group of disorders characterized by loss/ addition of less than $5 \mathrm{Mb}$ of genetic material undetectable by simple karyotype and a particular phenotype. Our study presents the results of investigations of classical and molecular cytogenetic (FISH, Fluorescence in situ Hibridization) in 70 children showing different phenotypic manifestations, such as multiple congenital anomalies, dysmorphic appearance, mental retardation, obesity. After performing classical cytogenetic technique of the 70 cases, in four girls there were diagnosed two visible structural chromosomal abnormalities: DiGeorge syndrome, Distal $18 q$ Deletion syndrome, $15 q$ Duplication syndrome, izocromosome $X q$ and one boy with 11q24-qter deletion and 38 numerical aberrations were identified: 33 cases of trisomy 21, two cases of monosomy $X$, two cases of poly $Y$ syndrome and one double aneuploidy, trisomy 21 and poly $Y$. Using FISH (Fluorescence in situ Hibridization) technique in all the 32 cases, another 5 cases were diagnosed with Prader-Willi syndrome, one with the following: Angelman syndrome, Williams syndrome and $15 q$ Duplication Syndrome, two DiGeorge syndrome, one Jacobsen syndrome, 11q 23-qter deletion and one double aneuploidy. In our study, the efficacy of the classical cytogenetic technique in confirmation of the cases suspected by chromosome abnormality was $61.4 \%$ and the FISH technique, was 37,5\%.In our study, using both methods of diagnosis, we obtained confirmation of the genetic etiology in only $72.85 \%$ of the cases.

Keywords: cytogenetic, FISH, microdeletions, microduplications

\section{Introduction}

Microdeletions and microduplications syndromes are a well-defined group of disorders characterized by loss/addition of less than $5 \mathrm{Mb}$ of genetic material undetectable by simple karyotype and a particular phenotype (1).

Even though the conventional cytogenetic analysis karyotyping is useful in identification of many syndromes, small structural chromosomal rearrangements as in microdeletion or microduplication syndromes, and cryptic translocations will be under the limit of detection (2). The molecular cytogenetics technique Fluorescent in situ hybridization (FISH) relies on the combination of two techniques: conventional cytogenetics and molecular genetics (3).

*email: danielpopa78@gmail.com 
The introduction of molecular cytogenetic FISH technique as a diagnosis method made possible the confirmation of chromosomal abnormalities below the optical resolution, unidentified by standard cytogenetic techniques. The method consists of linking a specific area of a chromosome with their complementary target DNA sequences in metaphase chromosomes or interphase cells. Although there are many hybridization probes, the locus-specific probes are used for the genomic localization of a gene, the detection of microdeletions and microduplications and of chromosomal translocations in interphase cell nuclei. $(4,5)$

Is considered that FISH technology has three major advantages: one is the test performances regarding the high sensitivity and specificity, the second is that it can be used on metaphase chromosomes as well as on interphase nuclei, and the third is the fact that visualization of hybridization signals at the single-cell level. (6)

Our study presents the results of investigations by classical cytogenetic and molecular FISH (Fluorescence in situ hybridization) in 70 children presenting phenotypic manifestations such as multiple congenital anomalies, dysmorphic features, intellectual disability, obesity for which a microdeletion/microduplication syndrome was suspected.

\section{Materials and methods}

In the Laboratory of classical and molecular Cytogenetics of the Oncology and Hematology Ward of Emergency Hospital for Children Louis Turcanu Timisoara, 70 samples from70 children there were performed and analyzed, both by conventional cytogenetic and molecular technique (FISH), having different phenotypic manifestations such as: multiple congenital anomalies, dysmorphic features, mental retardation and obesity. Clinical suspicion for the 70 patients is shown in Figure 1.

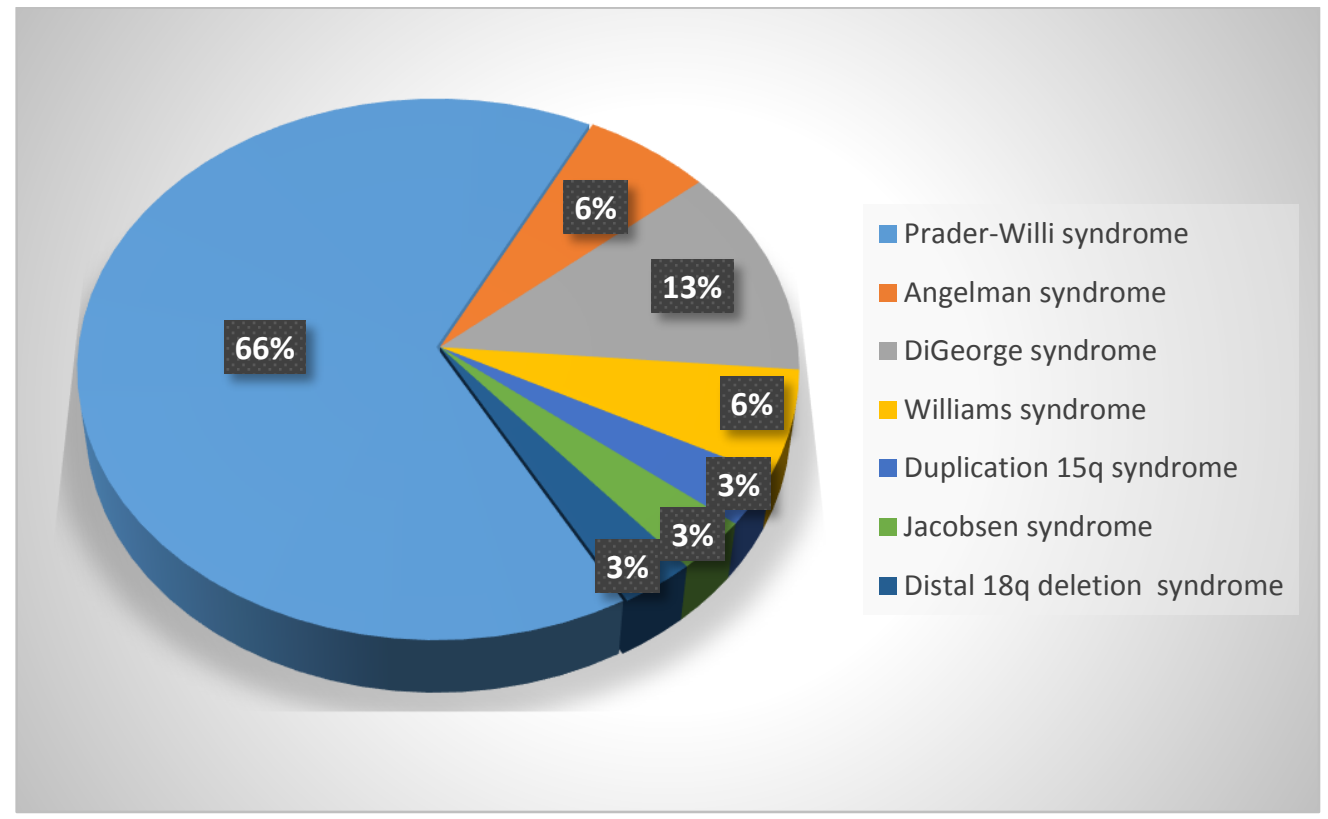

Figure 1. Abberrations identified in the study lot

Cytogenetic analyses were performed from peripheral venous blood by harvesting the cells for 72 hours, with the culture medium PBMax Karyotyping favorite (Gibco). In order to prepare metaphase cells, each sample was exposed to mitotic inhibitors, hypotonic solution $(\mathrm{KCl} 0.075 \mathrm{M})$ and fixed (absolute methanol: glacial acetic acid, 3:1). Cell suspension was mounted on the microscope glass slides and air dried. The samples were processed using $G$ banding technique. We evaluated 30 metaphases for each patient respecting the terms of quality protocol.

Subsequently, in all patients we applied the FISH technique using a specific probe correlated with the clinical suspicion or indicated by the karyotype. In order to achieve interphase or metaphase FISH 
technique we used genetic locus probes Metasystem: XL SNRPN (Small nuclear ribonucleoprotein polypeptide N, 15q11) Prader Willi, Angelman UBE3A(ubiquitin protein ligase E3A, 15q11) XL, XL TUPLE1(or HIRA - HIR histone cell cycle regulation defective homolog A, 22q11.2) DiGeorge, XL PML (promyelocytic leukemia,15q24)/RARA (retinoic acid receptor-alpha,17q21)Dual Fusion, XL MLL breakapart, Cytocell aquarius: Williams- Beuren (WBS) and there were read 300 cells for each case.

Fluorescence in situ Hybridization(FISH) was performed using the Metasystem and Cytocell aquarius FISH microdeletion probes kit. Slides were immersed in $+37{ }^{\circ} \mathrm{C} 2 \mathrm{xSSC}$ (SSC: 20x Salinesodium citrate buffer) for 30 min and then dehydrate in alcohol $70 \%, 80 \%$ and $100 \%$ for 2 minutes each. Slides were denatured at $+73^{\circ} \mathrm{C}$ (in a pre-warmed water bath) for $2 \mathrm{~min}$ and rinsed in ice-cold series of alcohol $70 \%, 80 \%, 100 \%$ for 2 minutes each. Slides were put on a slide warmer $\left(40^{\circ} \mathrm{C}\right)$ and applied 10ul probe and hybridized overnight at $37^{\circ} \mathrm{C}$. After overnight hybridization slides were washed in 0,4X SSC 0,3\% NP40 solutions at $73 \mathrm{C}$ for 2 minutes and rinsed in $2 \mathrm{X}$ SSC solution. For each case, a minimum of 300 cells were evaluated by using a fluorescent microscope. The best images were captured using the camera mounted on the microscope attached to a computer with karyotyping and FISH software.

\section{Results and discussions}

After performing classical cytogenetic technique of the 70 cases, four girls there were diagnosed with two visible structural chromosomal abnormalities: DiGeorge syndrome (Figure 2), 15q Duplication syndrome (Figure 3), distal 18q Deletion syndrome, (Figure 4), izocromosome Xq (Figure 5), one boy was diagnosed with Jacobsen syndrome (11q23-qter deletion) (Figure 6) and 38 numerical aberrations were identified: 33 cases of trisomy 21, two cases of monosomy X, two cases of poly $\mathrm{Y}$ syndrome and one double aneuploidy, trisomy 21 and poly $\mathrm{Y}$.

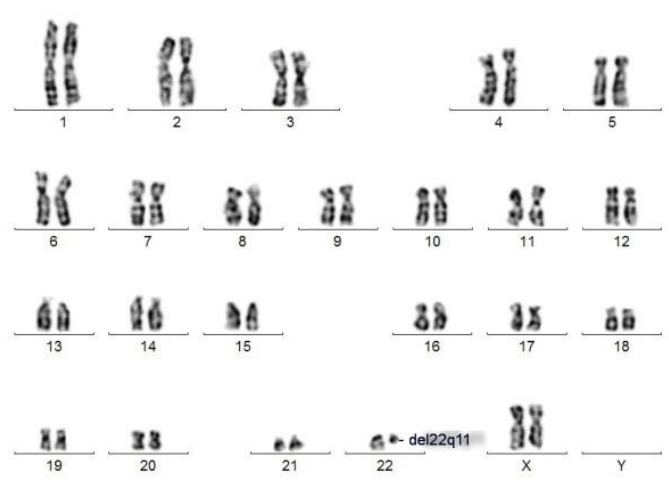

Figure 2. Karyotype: 46, XX, $\operatorname{del}(22)(q 11.2 ; q t e r)$

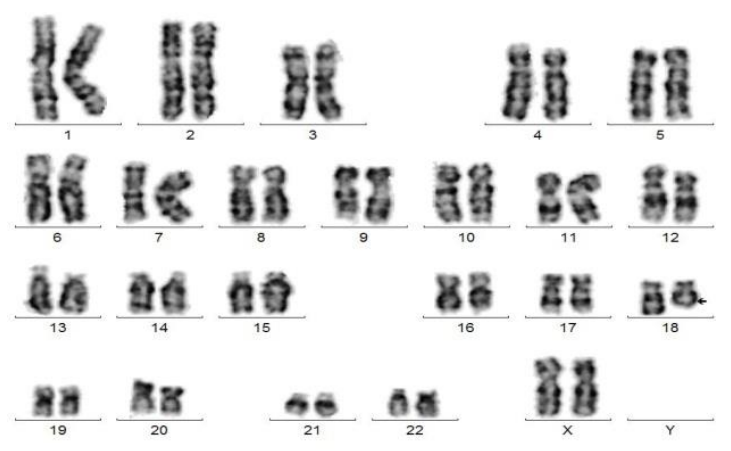

Figure 4. Karyotype: 46, XX, del (18)(qter)
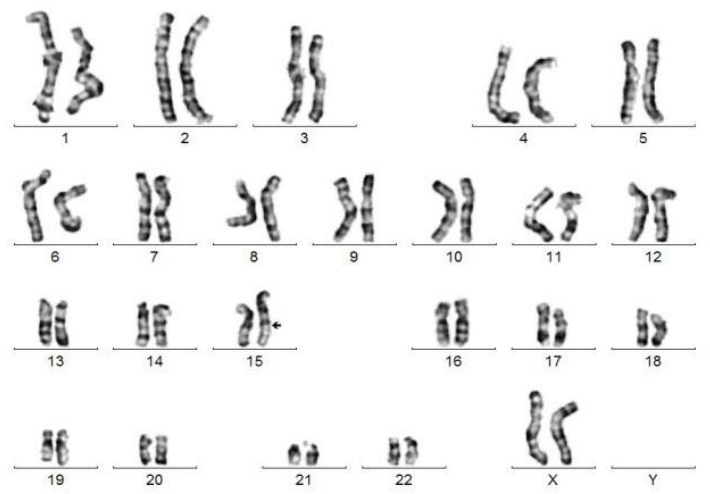

Figure 3. Karyotype: 46, XX, $\operatorname{dup}(15)(\mathrm{q} 21 ; \mathrm{q} 24)$

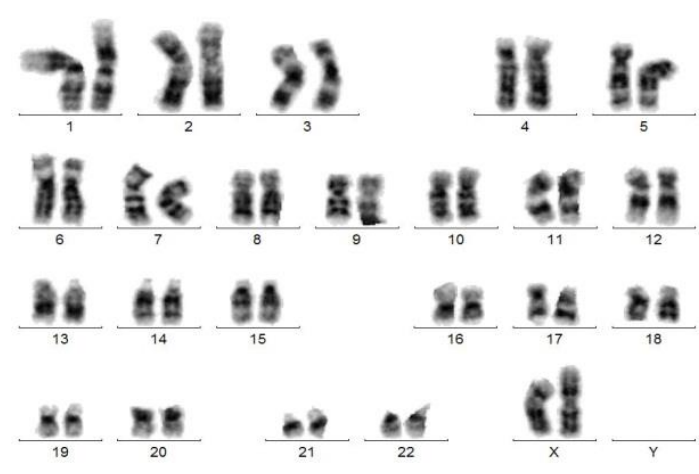

Figure 5. Karyotype: 46, X, i (Xq) 


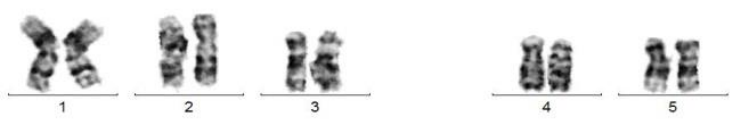
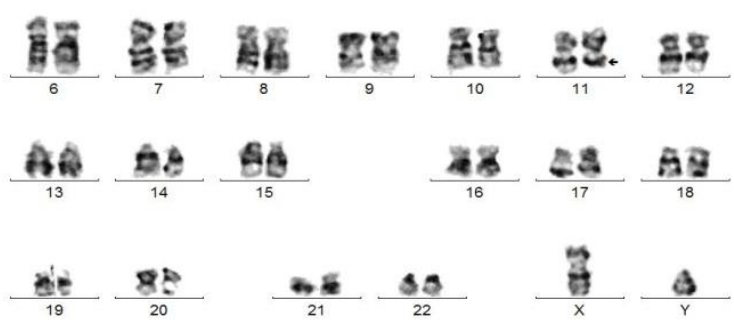

Figure 6. Karyotype: 46, XY, del (11)(q23;qter)

For 32 cases FISH technique was done and allowed us the diagnosis of 5 cases with Prader Willi syndrome (Figure 7), a case with Angelman syndrome (Figure 8), a case with Williams syndrome (Figure 9), two cases with DiGeorge syndrome (Figure 10), one case with 15q duplication syndrome (Figure 11) another one with 11q24-qter deletion (Figure 7).

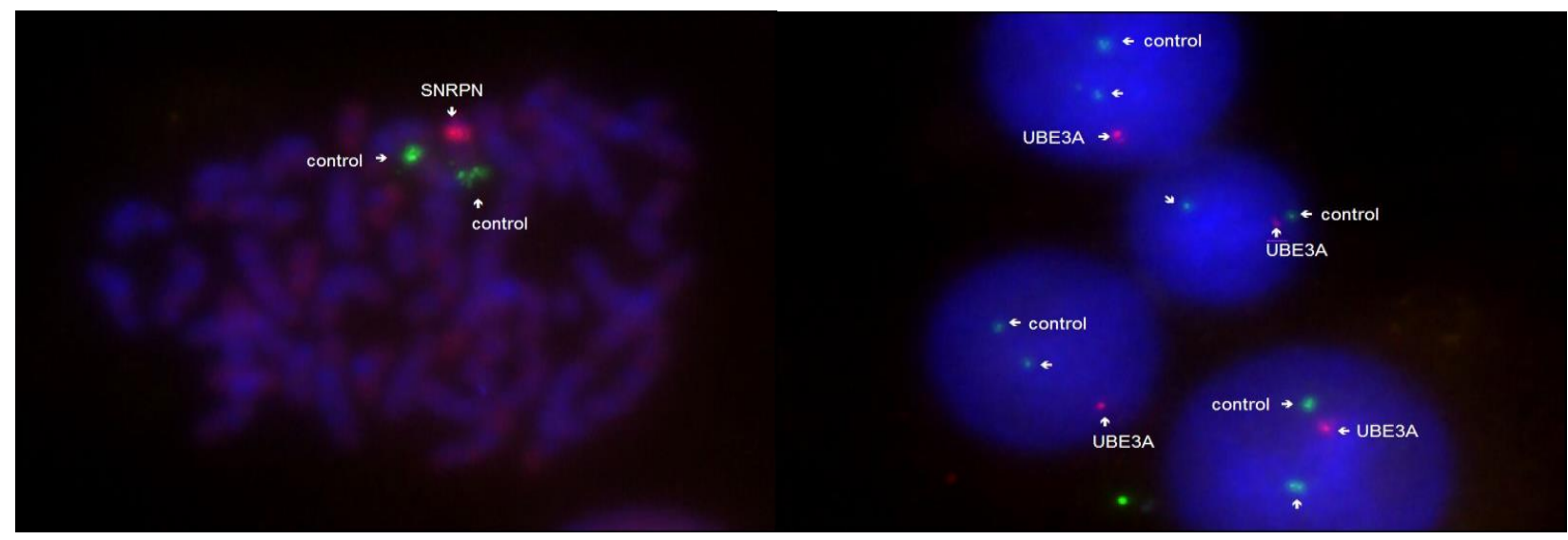

Figure 7. FISH XL SNRPN Prader- Willi: 15q11 sample SNRPN - orange, 15qter control sample - green. The only orange signal is normally present on chromosome 15
Figure 8. FISH XL UBE3A Angelman: 15q11 sample UBE3A (ubiquitin protein ligase E3A) orange, 15qter control sample - green. The only orange signal is normally present on chromosome 15

In the little girl with $15 \mathrm{q}$ duplication we used XL dual fusion probes PML (promyelocytic leukemia) / RARA (retinoic acid receptor-alpha) or checking subcentromeric and telomeric regions of genes PML and XL SNRPN (Figure 11). Of the three regions examined only PML gene was duplicated. In the 11q24-qter deletion we used XL MLL breakapart probe (Figure 12). 

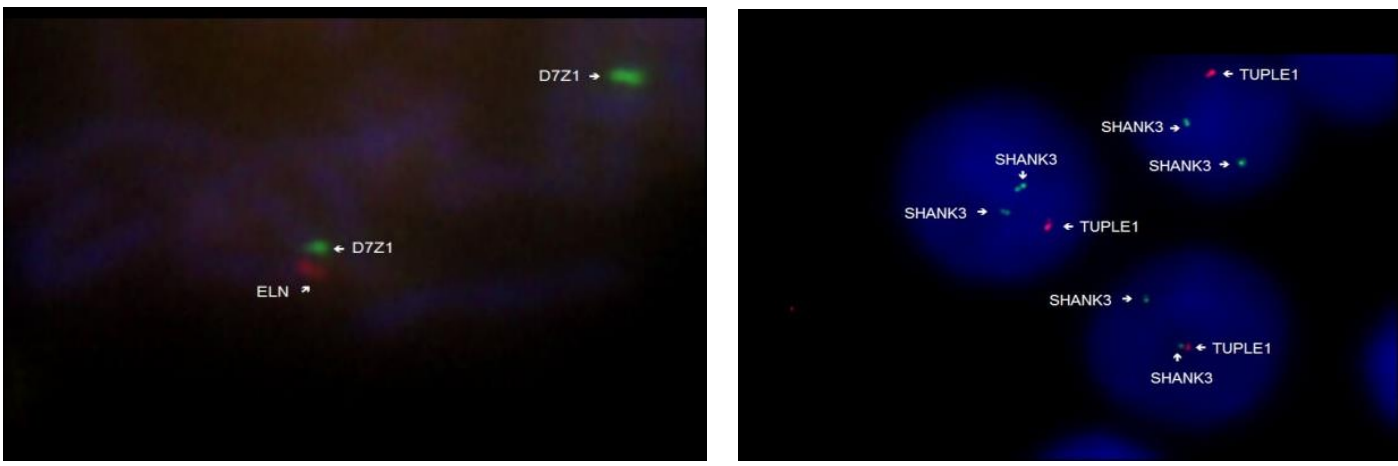

Figure 9. FISH: LSI 7q11.23 ELN (elastin) sample (Williams-Beuren,

ELN) - orange, control sample centromeric 7 D7Z1- green. The only orange signal is normally present on chromosome 7

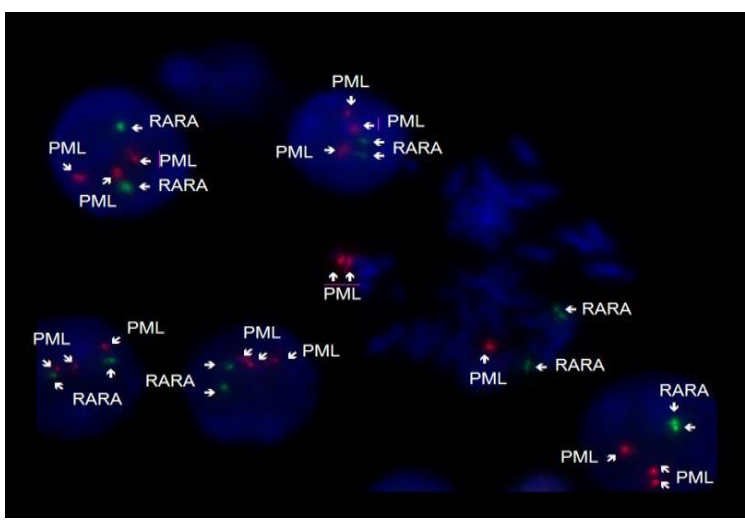

Figure 10. FISH: XL tuple TUPLE1 22q11.2 DiGeorge sample (HIRA- HIR histone cell cycle regulation defective homolog $\mathrm{A}$ ) orange, SHANK3 control sample $22 q 13$ - green. The only orange signal is present on chromosome 22 , normally.

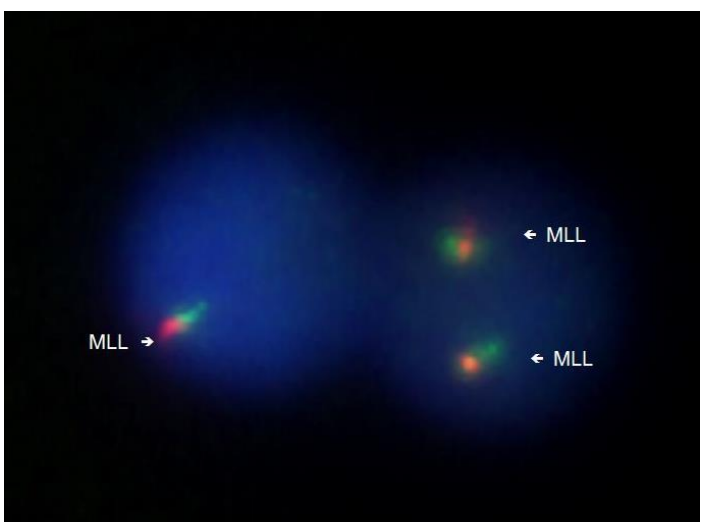

Figure 11. FISH XL PML / RARA Dual Fusion: 15q24 sample PML orange, 17q21 sample RARA - green.

Chromosome 15 normally shows a single orange signal and the duplication case shows two orange signals.

Figure 12. XL MLL FISH: 11q23 sample. Right: both chromosomes 11 in these regions. Left: one chromosome 11 in these regions

Analyzing the results of this retrospective study we have found arguments sustaining the advantages of FISH techniques versus classical cytogenetic. The classic $G$ banding cytogenetic technique has several limitations: those related to resolution - chromosomal abnormalities can be detected over 4-5 Mb, requiring the existence of metaphase chromosomes, which means getting cells in division phase (thus, a longer period of time until getting a result, due to the necessity of a cell culture) and the difficulties to elucidate chromosomal rearrangements, especially complex ones.

In our study, confirmation of the diagnosis by FISH is 37.5\%. Obviously, there are limitations in detecting chromosomal abnormalities by FISH technique. These relate to the resolution (using marking 
chromosomes in metaphase - about 2-5 Mb, using DNA marking in interphase - about 0.2 to $2 \mathrm{Mb}$ and about 5-500 Kb marking chromatin fiber or elongated chromosomes (special techniques)).

The decision of initiating a FISH protocol is usually decided by a clinical geneticist when the patient's clinical features orients the diagnosis. In cases with unclassified clinical features, the standard karyotype by $\mathrm{G}$ banding methods is followed by FISH in order to clarify the diagnosis. The time criterion is a key factor when the period in view of a diagnosis has to be shortened.

FISH technique can provide excellent results in the diagnosis of chromosomal abnormalities, although the information on a fragment/ fragments or chromosome/ marked chromosome can be limited, including the information on the entire chromosome set (unless that marks all pairs of chromosomes entirely). Microdeletion syndromes for whom the phenotype is well describe as Di George syndrome (del22q11.2) (7), Angelman syndrome (del15q11-q13) (8), Miller-Dieker syndrome (del17p13.3) (9), Prader-Willi syndrome (del15q11-q13) (10), Smith-Magenis (del17p11.2) (11), Williams syndrome (del7q11.23) (12), Rubinstein-Taybi syndrome (del16p13) (13), Jacobsen syndrome (del11q23-qter) (14) can be diagnosed in most cases by using FISH analysis.

Currently, the sensitivity and the specificity of the FISH techniques sustain their use in diagnosis of abnormalities, complementary to classical cytogenetic techniques with human chromosome banding. In our study, using both methods of diagnosis, we obtained confirmation of the genetic etiology in a $72.85 \%$ of the cases.

These results allow us to consider that cytogenetic analysis can be useful in investigating children with genetic disorders of unknown origin, as a confirmation of the clinical diagnosis and the support for appropriate genetic counseling. In such cases with clinical suspicion of syndromes caused by microdeletions, standard cytogenetics has a low, but orienting rate (12.5\% of confirmed cases), sustaining the use of molecular cytogenetic techniques as the next step of the algorithm. FISH technique has proven molecular confirmation in $32.25 \%$ of cases. For the other 2 cases suspected of PWS syndrome, the confirmation was obtained by methylation test. 14 patients suspected of PWS was not confirmed, and this probably by the etiology of the mutation in the inactivation centre.

For a rapid and cost efficient diagnosis is very important to choose the correct diagnostic test. When the phenotype is very suggestive for a specific microdeletion/microduplication syndrome, FISH analysis is the first test to be used. For the patients exhibiting complex phenotypes, or for the cases where a clinical diagnosis is not very clear, other methods of investigation should be considered. Multiplex Ligation-dependent Probe Amplification (MLPA) and comparative genomic hybridization $(\mathrm{CGH})$ allow an overview of genetic imbalances for multiple chromosomal regions and for those complex cases the use of above mentioned methods of analysis will be more cost efficient than the use of FISH analysis repeatedly. After the identification of chromosomal imbalances by using MLPA or CGH, FISH analysis should be recommended as a confirmation test.

\section{Conclusions}

The use of interphase FISH has been particularly fruitful for cancer cytogenetics, where the detection of recurrent chromosomal abnormalities and clonal evolution is crucial for classifying different types of tumors, selecting treatment protocols, and monitoring outcomes. Even with the introduction of genomic technologies like microarray analysis and exome sequencing, FISH analysis remains a very usefull technique for clinical practice.

\section{Reference}

1. MALCOLM, S., Prenat. Diagn., 16, nr. 13, 1996, p. 1213-9.

2.PANIGRAHI, I., JAIN, P., DIDEL, S., AGARWAL, S., MUTHUSWAMY, S., SAHA,

A., Neurol. India., 66, nr. 5, 2018, p.1370.

3.SUKAROVA-ANGELOVSKA, E., PIPERKOVA, K., SREDOVSKA, A., ILIEVA, G., KOCOVA, M., Prilozi., 28, nr. 2, 2007, p. 87-98. 
4.CHRISTIAN, S.L., BRUNE, C.W., SUDI, J., KUMAR, R.A., LIU, S., KARAMOHAMED, S., Biol. Psychiatry, 63, nr. 12, 2008, p. 1111-7.

5.SHAFFER, L.G., in: Dracopoli NC, Haines JL, Korf BR, Morton CC, Seidman CE, Seidman JG, Hoboken, N.J., U.S.A., John Wiley \& Sons, Inc.; 2001

6. CUI, C., SHU, W., LI, P., Front. Cell. Dev. Biol., 4, 2016, p. 89.

7.DRISCOLL, D.A., SALVIN, J., SELLINGER, B., BUDARF, M.L., MCDONALD-MCGINN, D.M., ZACKAI, E.H., J. Med. Genet., 30, nr. 10, 1993, p. 813-7.

8. MONAGHAN, K.G., WIKTOR, A., VAN DYKE, D.L., Genet. Med. Off J. Am. Coll. Med. Genet., 4, nr. 6, 2002, p.448-50.

9.SREENATH NAGAMANI, S.C., ZHANG, F., SHCHELOCHKOV, O.A., BI, W., OU, Z., SCAGLIA, F., J. Med. Genet., 46, nr.12, 2009, p. 825-33.

10.CASSIDY, S.B., FORSYTHE, M., HEEGER, S., NICHOLLS, R.D., SCHORK, N., BENN, P., Am. J. Med. Genet. 68, nr. 4, 1997, p. 433-40.

11.VLANGOS, C.N., WILSON, M., BLANCATO, J., SMITH, A.C.M., ELSEA, S.H. Am. J. Med. Genet. A. 132A, nr. 3, 2005, p. 278-82.

12. ElÇIOGLU, N., MACKIE-OGILVIE, C., DAKER, M., BERRY, A., Acta Paediatr. 87, nr. 1, 2007, p. 48-53.

13.SCHORRY, E.K., KEDDACHE, M., LANPHEAR, N., RUBINSTEIN, J.H., SRODULSKI, S., FLETCHER, D., Am. J. Med. Genet. A. 146A, nr. 19, 2008, p. 2512-9.

14. SYRROU, M., J. Med. Genet., 38, nr. 9, 2001, p. 621-4.

$\overline{\text { Manuscript received: } 07.04 .2020}$ 